\title{
Design and characteristics assessment of wireless vibration sensor for buildings and houses
}

\author{
Suherman, Fahmi, Ulfa Hasnita, Zul Herri \\ Electrical Engineering Department, Universitas Sumatera Utara, Medan, Indonesia
}

\begin{tabular}{l}
\hline \hline Article Info \\
\hline Article history: \\
Received Apr 15, 2020 \\
Revised Oct 30, 2020 \\
Accepted Dec 5, 2020 \\
\hline
\end{tabular}

\section{Keywords:}

Home monitoring

Sensor installation

Vibration sensor

Wireless vibration sensor

\begin{abstract}
This paper reports the wireless vibration detector design and characterization for practical applications. System is built by using the ATmega microcontrollers, working on a free license $433 \mathrm{MHz}$ frequency. Hardware characteristics are defined through experimental assessments. Assessment mainly on sensor output and sensor installation characteristics. As results, hardware is working as expected, where vibration level achieves at most $13 \%$ detection for $12 \mathrm{~g}$ vibration source. The vertical axis of the MPU6050 vibration detector results 87.5 times higher detection than in horizontal axis. Detected vibration increases from $1.03 \mathrm{~g}$ to $2.61 \mathrm{~g}$ when source-sensor distance is shortened from $10 \mathrm{~cm}$ to $2 \mathrm{~cm}$. The aluminium sheet as sensor pad causes detection of 8.69 times higher than on ceramic pad. The lower the detection period the better the detection amplitude. However, the lower the period, the higher the consumed power. Microcontroller sleep mode is not suitable for short period detection. The node-based data validation to avoid transmitting false detection is not influencial for short period detection.
\end{abstract}

This is an open access article under the CC BY-SA license.

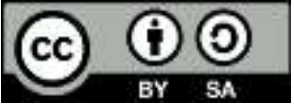

\section{Corresponding Author:}

Suherman

Electrical Engineering Department

Universitas Sumatera Utara

Jl. Almamater, Kampus USU, Medan, Indonesia

Email:suherman@usu.ac.id

\section{INTRODUCTION}

Vibration sensor is useful to detect minor or major replacements, such as for engine vibration sensing or even for earthquake early detection. Engine sensors are useful for preventive maintenance and performance monitoring, while major earthquake detection is important for preventing victims and mostly aimed to give early warning for home and office applications. Vibration sensors for maintenance and monitoring applications should be precise enough. Vibration detection for industrial application is also very important which requires precision sensor. While in some cases, such as in earthquake detection and cyclone pattern sensing, sensor sustainability is preferred [1] as sensor should be tough enough against rough and harsh environment. It is very important to avoid victims during the event.

There are not many available sensing products on market. Some precision sensors are produced and attached to commercial product, such as engine-attached sensors. Stand alone sensors for commercial applications such as home and building security are rarely found [2,3]. Although this research does not focus on how to produce the sensor, the work identifies considerations and requirements for sensor being used for buildings and houses applications so that an alternative sensor product can be optimized for this application.

Vibration sensors have been some research issues, including the use of optical sensor to provide precise detection as proposed by Nishino et al [4]. Sensor was devised by using a single mode optical fiber arranged in circle. Changes on the circle radius due to vibration result variations on the received optical 
signals. This optical-based vibration sensor is able to detect as low $10 \mathrm{~Hz}$ as vibration source. Optical sensor requires one solid side so that vibration in opposite side influences the ring radius. Other proposed sensor is made from piezoceramic [5] that enables vibrations to produce electrical parameters. Piezoceramic sensor is able to predict the concrete's strength that usually used for early-age or lifetime concrete strength monitoring. Electrochemical-based vibration sensor determines vibration based on electrical and chemical characteristics [6]. Nano-generator sensor makes use nano technology [7]. Thin film sensor uses properties of thin film materials [8]. Magnetic sensor generates magnetic variation due to vibration [9]. However, most sensor products are experimental sensors that are not widely available in market.

Sensor network is used for many applications such as animal population monitoring, agriculture application, environmental monitoring, security surveillance, smart building, and healthcare applications [10]. Sensor network for building monitoring is aimed at determining building construction performance [1113], building security [14-17], and object localization within buildings [18, 19]. Sensor network implementations in buildings and offices can be integrated with the existing power installation [20] as well as installed in the separated ducting system [21].

Sensor network implementations have been proposed by many researchers. Thaker [22] developed a low-cost wireless sensor network for industrial and building automations based on WiFi network and integrated sensor system, connected to a Linux web server using PHP run-time environment. Muheden at al [23] developed the home or industrial surveillance system for fire safety which sensed gas, flame, temperature, and humidity. Both [22] and [23] focused on system implementation. Meanwhile, Aguirre et al [24] combined WSN architecture and an Android-based application for monitoring train transportation by determining user density, link interferences and communication modes. However, the research focused on the analysis of wireless channel and its estimation.

Sensor validation is used to avoid false detection [25] and false data transmission. Sensor validation is performed in either sensor node and/or server [26]. Data validation can either use statistical methods or machine learning method. Statistical method is not a real-time method as data should be collected before being analyzed. The method is applicable only in server. Machine learning techniques such as one-class quarter sphere SVM have been applied for identifying outliers [27]. Machine learning is also too complicated for node based validation as resources are limited and machine learning requires training data pattern. Complexity reduction has been performed in [28], however, retraining the method may require more memory space for data buffering. Simple data validation methods have been proposed by [26, 29].

This paper explores the installation characteristics when sensor is installed for the intended applications. This is not yet explored deeply in existing work, so that the results may fill the research gap. The paper is organized as follows: sensor design and evaluation methods are discussed in next section, followed by evaluation method and result discussion. Paper is then concluded by some conclusions.

\section{PROPOSED DESIGN AND EVALUATION METHOD}

The designed system contains sensor node and server node. Sensor node is constructed by the ATmega328 microcontroller, the MPU6050 vibration sensor, and the FST1000 amplitude shift keying (ASK) transmitter. ATmega328 microcontroller orders the MPU6050 to sense vibration in thre directions $\mathrm{x}, \mathrm{y}$ and $\mathrm{z}$ axes. The detection is performed every predetermined time period. Data is then processed by the microcontroller either by using validation or not. Data is then sent to server via ASK transmitter working on frequency of $433 \mathrm{MHz}$. The server node is built by CZS3 ASK receiver and ATmega8 microcontroller. ASK receiver keeps receiving data at frequency of $433 \mathrm{MHz}$. The received data is forwarded to ATmega8 to be processed. ATmega8 is connected to PC to record data through USB connection.

On sensor node as shown in Figure 1(a), MPU6050 senses vibration in term of gravity $\left(\mathrm{g}\right.$, in $\left.\mathrm{m} / \mathrm{s}^{2}\right)$ and is controlled by ATmega328. Vibration sensing period is set from $150 \mathrm{~ms}$ to $250 \mathrm{~ms}$. Sensor reading was assessed either by sequential or sleep mode to conserve energy. Sleep mode uses SLEEP_MODE_PWR_DOWN function in ATmega328. Sensor data is then processed either by using peak validation [26] or not. Data is then sent to server node by using the $433 \mathrm{MHz}$ free license ASK transmitter. Circuit can be supplied by 220 Vac or 5Vdc. On the server side as shown in Figure 1(b), the CZS3 ASK receiver which is controlled by ATmega8 receives data and passes it to computer through TTL bit level converter. Circuit is serially connected to PC. Power source can be from 220Vac or from PC through USB connection.

In order to obtain sensor output and installation characteristics, the evaluation construction is set up as depicted in Figure 1(c). The source of vibration is a free fall load of some objects of $3 \mathrm{~kg}$ mass. The sensor is attached to either ceramic or aluminum materials as sensor pads. The vibration source is varied by using 1 , 2 , and 3 pieces of free fall objects. The point of falling object is referred as vibration source. Sensor-vibration source distance is set $2 \mathrm{~cm}$ and $10 \mathrm{~cm}$. A wall is set in between the falling point and sensor to protect sensor 
from the bumping object. The sensor pad material where sensor is attached is made from either ceramic or aluminum sheet. Detection period is set from 150 to $250 \mathrm{~ms}$. Vibration sensor is positioned on top of or attached to the sensor pad (aluminum or ceramic). Sensor and the vibration point are separated by a wood wall to protect the sensor. Sensor is connected to sensing node by using cable. Sensing node is powered by DC power supply. Radio link is set only a meter away as interferences are not the object of this paper. Receiving node is connected to PC via USB, including the powering.

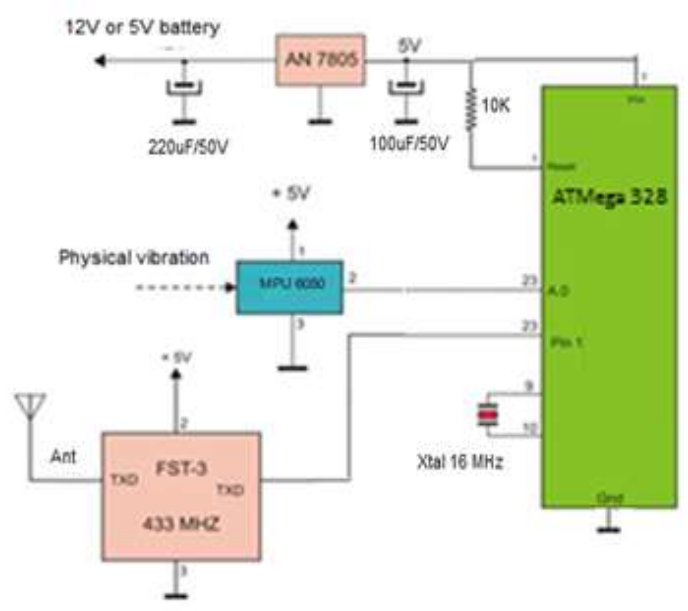

(a). ASK transmitter

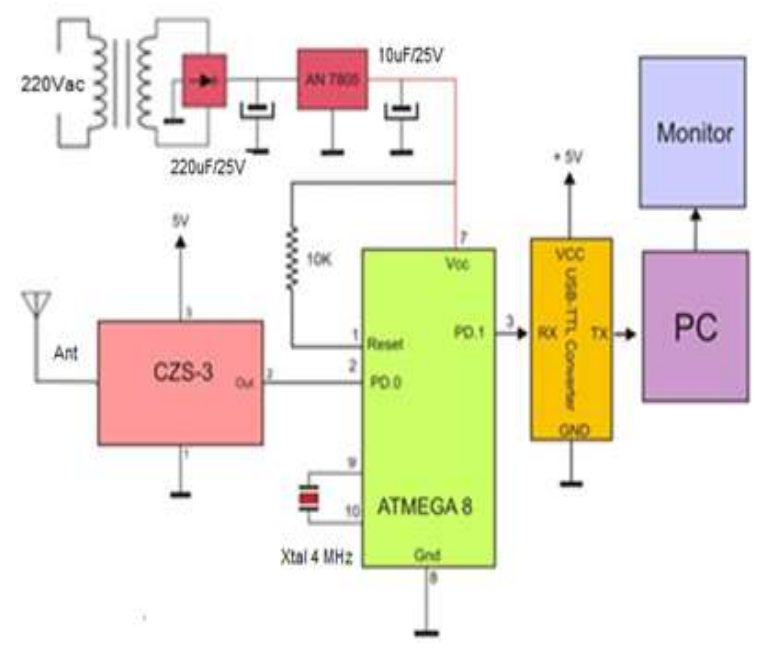

(b). ASK receiver

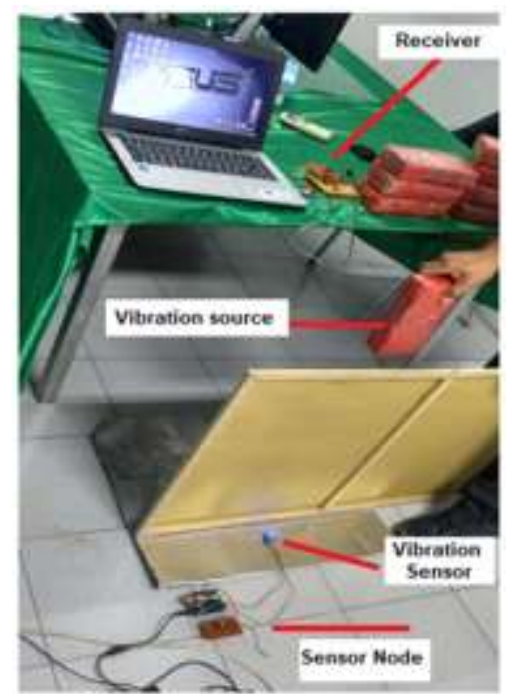

(c). Evaluation set up

Figure 1. System and evaluation designs

The validation technique is chosen as simple as possible to reduce processing time within the sensor node. Peak detection as shown in (1) and (2) [26] decides either the peak point value (Xn) is valid or not. It is invalid if the value is higher than previous and next data, $(\mathrm{Xn}-1)$ and $(\mathrm{Xn}+1)$ and the value is higher than $\partial$. Value of $\partial$ is the valid measurement threshold.

$\mathrm{Xn}-1<\mathrm{Xn}>\mathrm{Xn}+1$

$|\mathrm{Xn}-\mathrm{Xn}-1|>\partial$ and $|\mathrm{Xn}+1-\mathrm{Xn}|>\partial$ 


\section{EVALUATION RESULTS}

\subsection{Impact installation properties to vibration level}

MPU6050 is able to detect vibrations on $x-y-z$ axes. The $z$-axis is the vertical direction from the sensor surface, while $\mathrm{x}$ - and $\mathrm{y}$-axes are in horizontal directions. As sensor is laid down on ceramic or aluminium surface, the strongest vibration is in $\mathrm{z}$-axis. Figure 2(a) shows the average vibration values for 10 second detection of one falling object. The vertical or $\mathrm{z}$-axis detection is the strongest one, achieving 87.5 times stronger than $\mathrm{x}$ - and $\mathrm{y}$-axis. The average vibration detected by $\mathrm{z}$-axis is $1.0116 \mathrm{~g}$. The total vibration of the three axes is $1.0118 \mathrm{~g}$. This fact means that in any applications, in order to obtain maximum detection, vertical axis should be located on the most vibrating direction. The vibration source of $12 \mathrm{~kg}$ is equivalent to 120 Joules or $12 \mathrm{~g}$ for gravity acceleration of $10 \mathrm{~m} / \mathrm{s} 2$. A single falling object results vertical axis detection as plotted in Figure 2(b). The maximum vibration amplitude can be detected is $1.6 \mathrm{~g}$. This peak value is about $13 \%$ of the source value, $12 \mathrm{~g}$, which gives $13 \%$ detection efficiency.

The higher the vibration source the stronger the detected vibration. Figure 2(c) shows detected vibrations from $3 \mathrm{~kg}, 6 \mathrm{~kg}, 9 \mathrm{~kg}$ which produce peak detections of $0.37 \mathrm{~g}, 0.79 \mathrm{~g}$ and $0.99 \mathrm{~g}$ subsequently. Peak detection increases logarithmically to vibration source following the trend equation of $y=0.5688 \ln (x)-$ $0.248, \mathrm{x}$ is source mass and $\mathrm{y}$ is acceleration. The magnitude depends on the collision surface between source and surface where sensor located, as well as the distance of vibration point and sensor.

The longer the distance the smaller the impact as vibration travels through materials. Vibration sensor should be located to the vibration source as close as possible. By using $12 \mathrm{~kg}$ falling object, the experiment shows that the further the distance results the lower the peak amplitude. Figure 2(d) shows that 2 $\mathrm{cm}$ distance from contact point produces about $1.58 \mathrm{~g}$ higher than $10 \mathrm{~cm}$ distance, which is only $1.03 \mathrm{~g}$.

Solid conductive materials tend to reduce vibration waves. Flexible conductive materials pass on the vibration waves. The pad material where sensor is attached should be flexible enough to get better detection. Figure 2(e) shows detection patterns for sensor pad materials made of aluminium sheet and ceramic. The maximum vibration on aluminium sheet pad is 8.69 times higher than on ceramic pad.

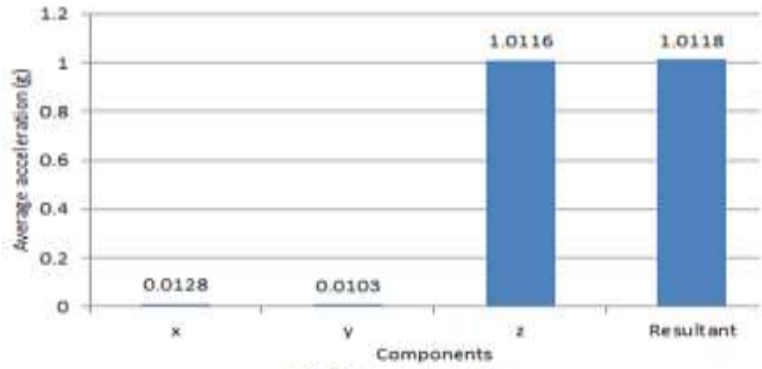

(a) Sensor direction

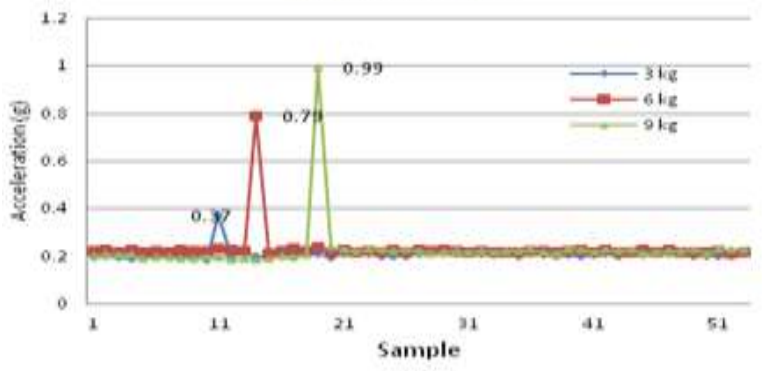

(c) Vibration source variation

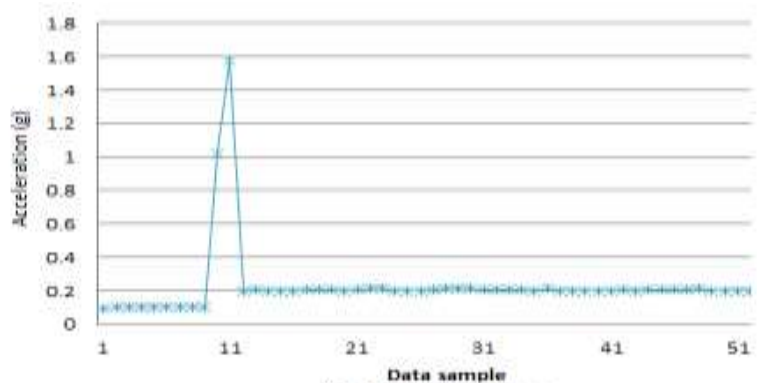

(b) Detection pattern

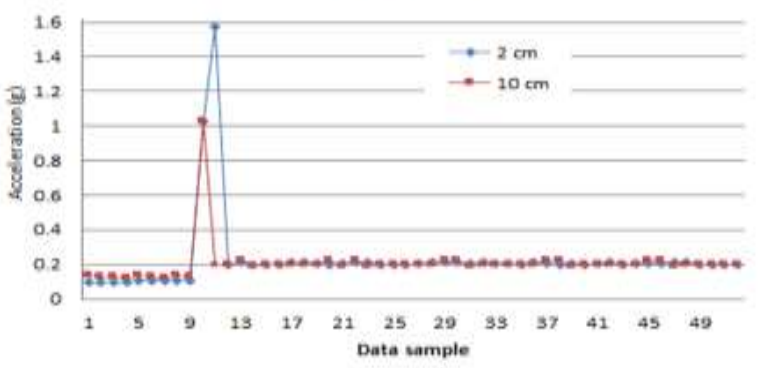

(d) Distance variation

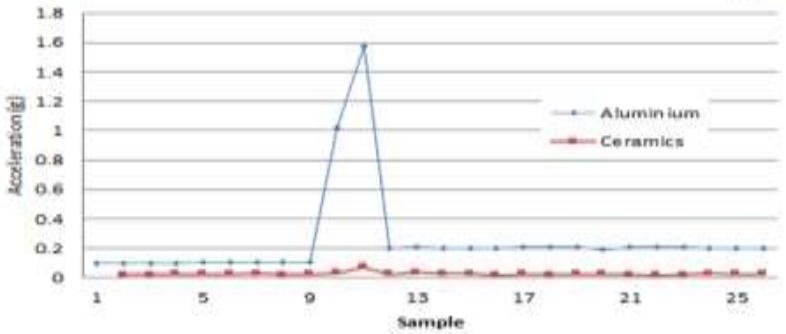

(e) Sensor pad impact

Figure 2. Installation impact to detection level 


\subsection{Detection setting impact}

Some vibrations occur in short period, others last longer. Since sensor detects vibrations in discrete time, it may not detect the maximum amplitude. Therefore, detection period should be as short as possible in order to detect high vibration amplitude. Experiment shows that with the same planned vibration source, 150 $\mathrm{ms}$ detection period is able to detect higher average vibration amplitude than of $200 \mathrm{~ms}$ and $250 \mathrm{~ms}$ detection periods as plotted in Figure 3(a).

However, if power consumption is an issue, shorter period may result higher power consumption. The same experiment recorded that $250 \mathrm{~ms}$ period absorbed lower power consumption than $200 \mathrm{~ms}$ and 150 ms period. Figure 3(b) shows that power consumption decreases linearly to vibration detection period. Detection quality and power consumption should be considered carefully depending upon the application requirement. For system with node installed in scarse power availability area, saving the power source by using longer period is suggested.

Impact of sleep mode is shown in Figures 3(c) and 3(d). Sleep mode objective is to reduce power consumption. Sleep mode in ATmega328 microcontroller reduces current up to $0.36 \mathrm{~mA}$ [30]. Employing sleep mode may reduce the overall power consumption. Sleep mode is important when detection occurs occasionally. In order to wake up microcontroller, interrupting signal is set. Since vibration detection sent by MPU6050 only uses one pin (pin 2) to send data, this pin can also be used to wake up microcontroller.

Figure 3(d) shows that sensor node power consumption decreases significantly when sleep mode is employed. However, since the experiment generated vibration by using falling object, the time of occurrence is very short. By the time the controller wakes up, the vibration data has gone. When sleep mode is employed, detection quality decreases significantly as shown in Figure 3(c). This happens as vibration data peak may contain only single vibration amplitude as illustrated in Figure 3(e). That is why the average acceleration detected by sensor is lower than when sleep mode is activated. In order to avoid detection failure, sleep mode should not be used when the nature of data is short time. Short period data may fail to detect when sleep mode is active.

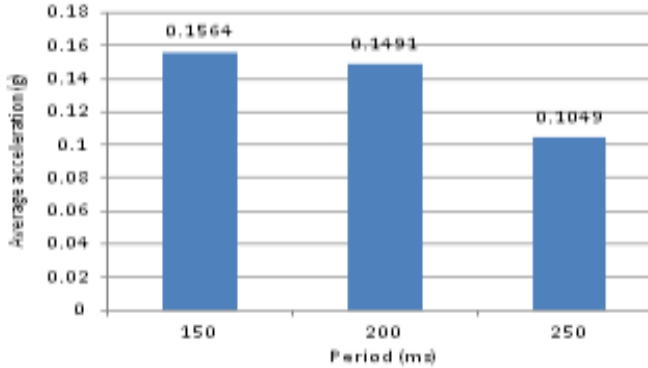

(a) Detection level vs detection period

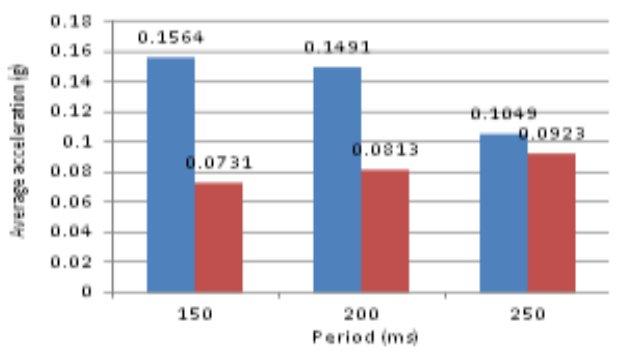

(c) Detection level vs sleep mode

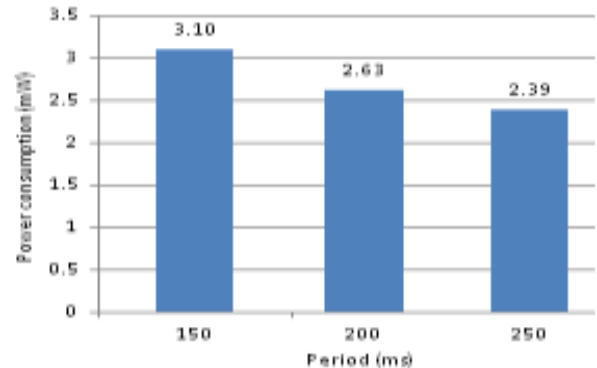

(b) Power consumption vs detection period

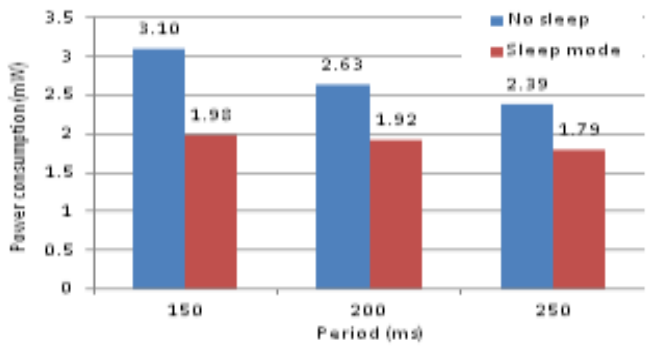

(d) Power consumption vs sleep mode

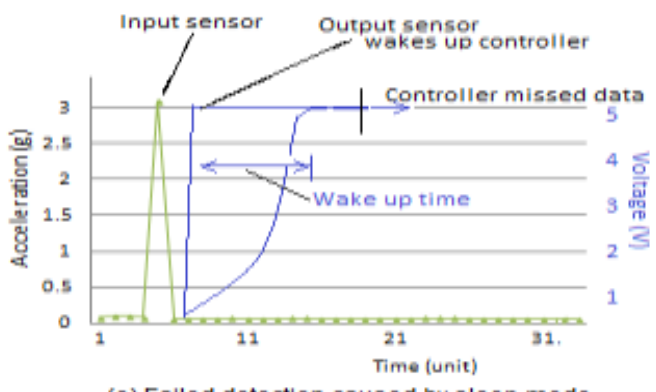

(e) Falled detection caused by sleep mode

Figure 3. Detection period and sleep mode impact 


\subsection{Data validation impact}

Data validation objective in sensor node is to prevent node sending invalid data to server. It is expected to avoid unnecessary transmission and may reduce power consumption [26]. However, the experiment shows that power consumption reduction is not significant and inconsistent as shown in Figure 4(a). The highest reduction is only $0.07 \mathrm{~mW}$. This can be explained as the nature of data appearance is short time. Data validation within microcontroller may take time and absorbs additional power. Therefore, the validation is not effective. Figure 4(b) shows that the capability of sensors decreases significantly when validation is applied. If data validation should be applied, then parameter should be chosen carefully, otherwise, detection may fail. As shown in Figures 4(b) and 4(c), peak data validation with $\delta=1$ results poor detection, while $\delta=2$ results fair detection.

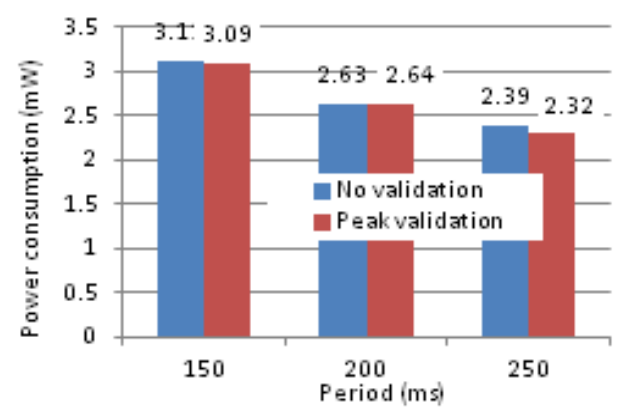

(a) Power consumption

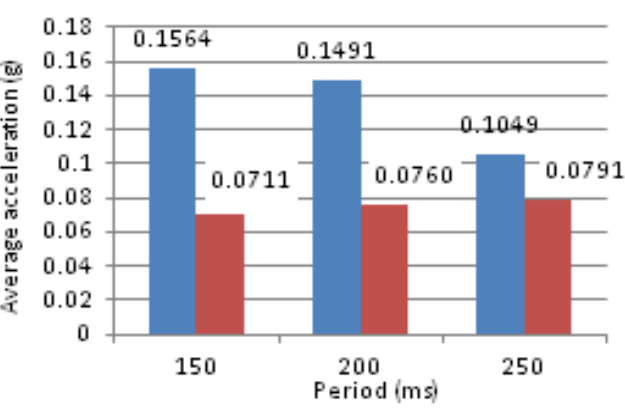

(b) Detection level for $\delta=1$

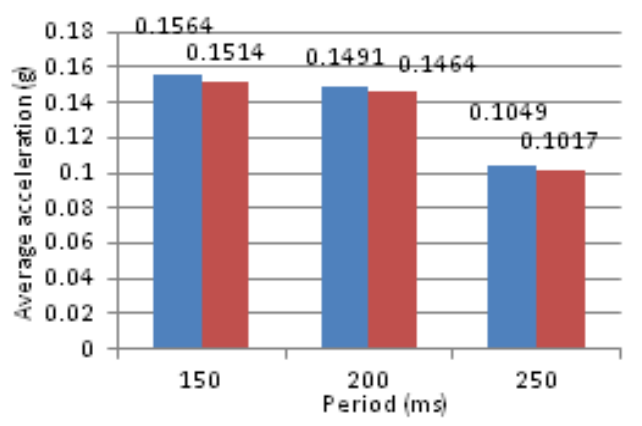

(c) Detection level for $\delta=2$

Figure 4. Node-based data validation impact

\section{CONCLUSIONS}

This paper discussed the wireless vibration sensor design and installation characterizations for building monitoring. The experiment was set up by using falling objects as vibration sources. The measurement shows that z-axis of MPU6050 sensor results 87.5 times higher detection than $\mathrm{x}$-axis and $\mathrm{y}$ axis. Detection efficiency obtained in this experiment is about $13 \%$ when the falling object value is $12 \mathrm{~g}$. Detected vibration increases when the vibration source is added from $3 \mathrm{~kg}$ to $9 \mathrm{~kg}$. Detected vibration also increases from $1.03 \mathrm{~g}$ to $2.61 \mathrm{~g}$ when vibration source and sensor distance gets closer from $10 \mathrm{~cm}$ to $2 \mathrm{~cm}$. The pad material where sensor is attached also determines the detection efficiency as flexible aluminium sheet causes 8.69 times higher detected vibration than on ceramic pad. Further, shorter detection period results better vibration detection as the nature of vibration source is short time. However, the shorter the detection period results the higher the power consumption. Sleep mode is able to conserve power; however, it is not suitable for short period vibration source. Finally, Sensor node-based data validation should be implemented carefully as incorrect parameter may result failed detection.

\section{ACKNOWLEDGEMENTS}

This research is funded by DIKTI through Magister Thesis Research Schema of 2020. 


\section{REFERENCES}

[1] A. S. Inashai, L. D. Sarno, "Fundamentals of earthquake engineering". John Wiley \& Sons, Ltd., 2008.

[2] P. Huihui, et al. "Analysis and design of a bioinspired vibration sensor system in noisy environment." IEEE/ASME transactions on mechatronics, vol. 23, no. 2, pp. 845-855, 2018.

[3] Zhou, Qianwei, et al. "Microphone-based vibration sensor for UGS applications." IEEE Transactions on Industrial Electronics, vol. 64, no. 8, pp. 6565-6572, 2017.

[4] Z. T. Nishino, K. Chen, and N. Gupta, "Power Modulation-Based Optical Sensor for High-Sensitivity Vibration Measurements," IEEE Sens. J., vol. 14, no. 7, pp. 2153-2158, 2014.

[5] J. Chen, P. Li, G. Song, Z. Ren, "Piezo-based wireless sensor network for early-age concrete strength monitoring". Optik, vol. 127, pp. 2983-2987, 2016.

[6] K. Sadeghipour, R. Salomon, S. Neogi, "Development of a novel electrochemically active membrane and'smart'material based vibration sensor/damper". Smart Materials and Structures, vol. 1, no. 2, p. 172, 1992.

[7] J. Chen, et al. "Harmonic-resonator-based triboelectric nanogenerator as a sustainable power source and a selfpowered active vibration sensor". Adv. Materials, vol. 25, no. 42, pp. 6094-6099, 2013.

[8] Y. Tanaka, D. Nguyen, T. Fukuda, A. Sano. "Wearable skin vibration sensor using a PVDF film". 2015 World Haptics Conference, pp. 146-151. IEEE.

[9] Y. Yamamoto, H. Eda, T. Mori, A. Rathore. "Three-dimensional magnetostrictive vibration sensor: development, analysis, and applications". J. of alloys and compounds, vol. 258, no. 1-2, pp. 107-113, 1997.

[10] SJ. Ramson, DJ. Moni. “Applications of wireless sensor networks-A survey”. In 2017 ICEEIMT, pp. 325-329. IEEE.

[11] M. Frei, C. Deb, R. Stadler, Z. Nagy, A. Schlueter. "Wireless sensor network for estimating building performance". Automation in Construction, vol. 111, p. 103043, 2020.

[12] S. Noye, R. North, D. Fisk. "A wireless sensor network prototype for post-occupancy troubleshooting of building systems". Automation in Construction, vol. 89, pp. 225-234, 2018.

[13] N. Naji, et al. "An Energy-Aware Wireless Sensor Network for Data Acquisition in Smart Energy Efficient Building". In 2019 IEEE 5th World Forum on IoT, pp. 7-12, 2019.

[14] WF. Cheung, TH. Lin, CY. Lin. "A real-time construction safety monitoring system for hazardous gas integrating wireless sensor network and building information modeling technologies". Sensors, vol. 18, no. 2, p. 436, 2018.

[15] S. Valenti, et al. "A low cost wireless sensor node for building monitoring". IEEE Workshop on Environmental, Energy, and Structural Monitoring Systems, pp. 1-6. IEEE, 2018.

[16] Q. Huang, C. Mao, Y. Chen. "A compact and versatile wireless sensor prototype for affordable intelligent sensing and monitoring in smart buildings". In Computing in Civil Engineering 2017 pp. 155-161, 2017.

[17] J. Wang, H. Shao. "Application of Wireless Sensor Network Technology in Security Control of Intelligent Buildings". Int. J. of Online and Biomedical Engineering (iJOE), vol. 14, no. 05, pp. 93-104, 2018.

[18] JD. Poston, RM. Buehrer, AG. Woolard, PA. Tarazaga. "Indoor positioning from vibration localization in smart buildings". In 2016 IEEE/ION Position, Location and Navigation Symposium (PLANS), pp. 366-372, IEEE.

[19] JD. Poston, RM. Buehrer, PA. Tarazaga. "A framework for occupancy tracking in a building via structural dynamics sensing of footstep vibrations". Frontiers in built environment, vol. 3, p. 65, 2017.

[20] P. Nikitin, SJ. Kelly. U.S. Patent No. 9,935,605. Washington, DC: U.S. Patent and Trademark Office, 2018.

[21] H. Yang, B. Kim, J. Lee, Y. Ahn, C. Lee. "Advanced wireless sensor networks for sustainable buildings using building ducts". Sustainability, vol. 10, no. 8, pp. 2628, 2018.

[22] Thaker. "ESP8266 based implementation of wireless sensor network with Linux based web-server," 2016 Symposium on Colossal Data Analysis and Networking (CDAN), Indore, 2016, pp. 1-5.

[23] K. Muheden, E. Erdem, S. Vançin. "Design and implementation of the mobile fire alarm system using wireless sensor networks". 17th Int. Symposium on Computational Intelligence and Informatics, pp. 243-246, 2016, IEEE.

[24] E. Aguirre. "Design and Implementation of Context Aware Applications With Wireless Sensor Network Support in Urban Train Transportation Environments," in IEEE Sensors, vol. 17, no. 1, pp. 169-178, 1 Jan.1, 2017.

[25] A. Fongen, F. Mancini. "Integrity attestation in military IoT". IEEE 2nd World Forum on Internet of Things, 2015,

[26] N. Mubarakah et al. "Node-based versus Server-based Data Validations in Internet of Things", in Proceeding of the 2nd Int. Conf. on Information Technology and Engineering Management, April 2, 2020.

[27] Z. Sheng, C. Mahapatra, C. Zhu, and VC Leung. "Recent advances in industrial wireless sensor networks toward efficient management in IoT", IEEE Access, vol. 3, 622-637, 2015.

[28] S. Xiong, Q. Ni, X. Wang, and Y. Su. "A connectivity enhancement scheme based on link transformation in IoT sensing networks". IEEE Internet Things J., vol. 4, no. 6, pp. 2297-2308, 2017.

[29] N. Alduais, et al.J. "Sensor node data validation techniques for realtime IoT/WSN application". 2017 14th Systems, Signals \& Devices (SSD) Multi conference, 2017.

[30] Atmel-42735B-ATmega328/P_Datasheet_Complete-11/2016 


\section{BIOGRAPHIES OF AUTHORS}

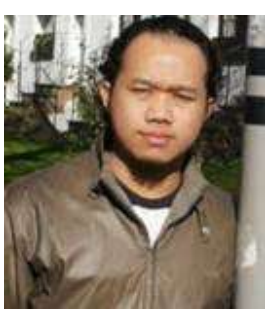

Suherman is a Senior Lecturer in electrical engineering department, Universitas Sumatera Utara. He completed B.Eng from this university in 2000 and obtained MSc and PhD from RMIT, Australia and De Montfort University, UK subsequently in 2009 and 2013. He also followed some courses in TU-Ilmenau, Germany and European Bioinformatics Institute, Cambridge, UK. His research interest covers communication network and protocols, computer network as well as applied communication techniques.

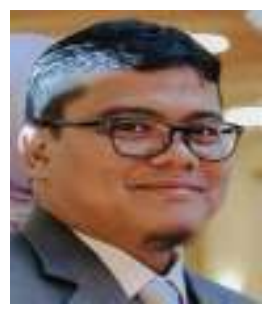

Fahmi is the head of electrical engineering department, Universitas Sumatera Utara. He completed his B.Sc, MSc and PhD from Bandung Institute of Technology-Indonesia, FHKarlsruhe-Germany, and University of Amsterdam-Netherland respectively. His research interest is in biomedical engineering and image processing.

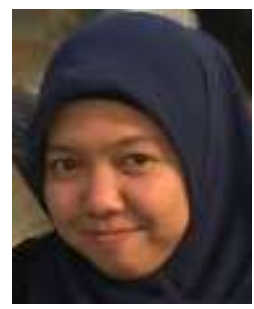

Ulfa Hasnita completed her Diploma and B.Eng degree within Universitas Sumatera Utara. She then completed her M.Eng degree from electrical engineering department, Universitas Sumatera Utara in 2019. Her research interest lies on electronics and computer engineering. She is currently a Lecturer within Akademi Teknik Dan Keselamatan Penerbangan (ATKP) Medan.

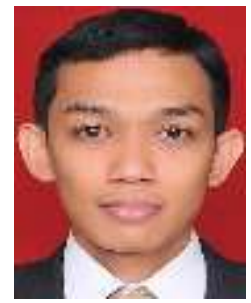

Zul Herri is a master student within Universitas Sumatera Utara starting in 2019. His research interest is in the field of computer engineering. 